\title{
Effects of ADAM10 and ADAM17 Inhibitors on Natural Killer Cell Expansion and Antibody-dependent Cellular Cytotoxicity Against Breast Cancer Cells In Vitro
}

\author{
DANG-HUAN PHAM ${ }^{1 *}$, JU-SUN KIM ${ }^{2 *}$, SANG-KI KIM ${ }^{2}$, DONG-JUN SHIN ${ }^{2,3}$, NGUYEN-THANH-TUNG UONG ${ }^{3}$, \\ HOON HYUN ${ }^{1}$, MEE SUN YOON ${ }^{4}$, SIN JAE KANG ${ }^{5}$, YOUNG JAE RYU ${ }^{5}$, JIN SEONG CHO ${ }^{5}$, \\ JUNG HAN YOON ${ }^{5}$, JI SHIN LEE ${ }^{6}$, DUCK CHO ${ }^{7}$, SOO-HYEON LEE ${ }^{8}$ and MIN HO PARK ${ }^{5}$ \\ ${ }^{1}$ Department of Biomedical Sciences, Chonnam National University Medical School, Gwangju, Republic of Korea; \\ ${ }^{2}$ Department of Companion \& Laboratory Animal Science, Kongju National University, Yesan, Republic of Korea; \\ ${ }^{3}$ Research Center for Cancer Immunotherapy, \\ Chonnam National University Hwasun Hospital, Jeollanam-do, Republic of Korea; \\ ${ }^{4}$ Department of Radiation Oncology, Chonnam National University Medical School, Gwangju, Republic of Korea; \\ ${ }^{5}$ Department of Surgery, Chonnam National University Medical School, Gwangju, Republic of Korea; \\ ${ }^{6}$ Department of Pathology, Chonnam National University Medical School, Gwangju, Republic of Korea; \\ ${ }^{7}$ Department of Laboratory Medicine \& Genetics, Samsung Medical Center, \\ Sungkyunkwan University School of Medicine, Seoul, Republic of Korea; \\ ${ }^{8}$ Department of Integrated Life Science and Technology, Kongju National University, Yesan, Republic of Korea
}

\begin{abstract}
Background/Aim: The inhibition of a disintegrin and metalloproteinase (ADAM) has the potential to become a novel approach for natural killer (NK) cell-based cancer immunotherapy. Thus, the aim of this study was to investigate the influence of ADAM10 and ADAM17 inhibitors on expanded $N K$ cell to enhance antibodydependent cellular cytotoxicity (ADCC) in breast cancer cell lines. Materials and Methods: NK cells were expanded in medium supplemented with an ADAM1O or ADAM17 inhibitor to prevent the shedding of soluble CD16/Fc $\gamma$ RIII. The expression level of CD16 and production of interferongamma $(I F N-\gamma)$ was detected by flow cytometry using specific antibodies. ADCC activity of expanded NK cells was estimated in trastuzumab treated breast cancer cell lines such as MCF-7, MDA-MB-231, SKBR3, and BT-474 cells. Results: The ADAM17 inhibitor increased the purity of
\end{abstract}

*These Authors contributed equally to this study.

Correspondence to: Min Ho Park, Department of Surgery, Chonnam National University Medical School, 160 Baekseo-ro, Dong-gu, Gwangju, 61469, Republic of Korea. Tel: +82 622206456, Fax: +82 622271635, e-mail: mhpark@chonnam.ac.kr

Key Words: ADAM inhibitor, breast neoplasms, CD16 receptor, NK cell. expanded NK cells to $90 \%$ after 14 days at 5 and $10 \mu \mathrm{M}$ in vitro ( $p=0.043)$. However, the expansion rate of $N K$ cells was decreased at $10 \mu M$ of the ADAM 17 inhibitor $(p=0.043)$. Inhibition of ADAM10 suppressed the expansion of NK cells, although the NK purity was increased at $1 \mu M$ of the inhibitor. The expression of CD16 was significantly increased at 1 and $5 \mu M$ of the ADAM17 inhibitor ( $p=0.046$, 0.028 , respectively) during the culturing period. Inhibition of ADAM10 reduced the expression of CD16 on NK cells. The cytotoxic activity of the ADAM17 inhibitor treated NK cells against MCF-7 $(p=0.039)$ and BT-474 $(p=0.027)$ cells was significantly elevated. The ADCC activity of NK cells treated with $5 \mu M$ of ADAM17 inhibitor was significantly increased against SKBR-3 and BT-474 $(p=0.027)$. Inhibition of ADAM17 increased the production of IFN- $\gamma$ in expanded NK cells. Conclusion: The inhibition of ADAM17 enhanced the purity of expanded NK cells and the ADCC activity of these cells against trastuzumab treated breast cancer cell lines.

A disintegrin and metalloproteinase (ADAM) belongs to the matrix metalloproteinase (MMP) family that plays a critical role in modulating the activity of several biological molecules and their inhibitors (1-3). The shedding of receptors is associated with the activation of enzymes that can cleave extracellular domains into soluble forms (3-5). Additionally, members of the MMP family control factors 
involved in the progression of cancer and infectious disease. ADAM10 and ADAM17 (tumor necrosis factor $\alpha$-converting enzyme) are up-regulated in breast cancer. Lendeckel et al. demonstrated that ADAM9, 12, and 17 are over-expressed in breast cancer (6). Furthermore, ADAM17 is involved in the shedding of IL-6R, a receptor expressed highly in inflammation and cancer $(3,7)$.

Natural killer (NK) cells are a part of the innate immune response that contribute to the eradication of virus-infected cells and cancer cells by natural cytotoxicity and production of immune modulatory cytokines $(8,9)$. NK cells express the CD16 (Fc $\gamma$ RIII) which mediates antibody-dependent cellular cytotoxicity (ADCC) and production of cytokines in response to antibody-coated cancer cells. It has been reported that CD16 expression and function of NK cells are regulated by $\operatorname{ADAM} 17(4,10)$ and treatment of $\operatorname{ADAM}$ inhibitors to NK cells enhanced their effector functions against cancer cells $(1,4,11)$. Recent studies showed that the expression level of CD16 on the surface of activated NK cells is reduced rapidly by efficient cleavage. These reports demonstrated that CD16 was cleaved from the cell surface by MMP and ADAM-17 after NK cell activation with stimulatory cytokines (IL-2 or IL-15) or tumor cells $(4,12)$. Their results suggest that inhibition of MMPs, such as ADAM-17 could reduce the cleavage of CD16 during the NK cells culture, and improve ADCC function of ex vivo expanded NK cells. Therefore, the inhibition of MMP family enzymes could be potentially a novel approach for NK cell - based cancer immunotherapy.

In the present study, we investigated the effects of ADAM10 and ADAM17 inhibitors on the proliferation of NK cells, as well as their activity during the long-term culture ex vivo.

\section{Materials and Methods}

NK cell expansion. The expansion of NK cells was performed by the previous reports $(13,14)$. In brief, peripheral blood mononuclear cells (PBMCs) from healthy donors were isolated by densitygradient centrifugation with Ficoll-Hypaque (d=1.077 g/mL; Lymphoprep; Axix-Shield, Oslo, Norway). Freshly prepared PBMCs were then co-cultured with 100 Gy gamma-ray-irradiated K562 cells in RPMI1640 media (Welgene, Gyeongsan, South Korea) with $10 \%$-heat inactivated FBS, 100 units/ml of penicillin, $100 \mu \mathrm{g} / \mathrm{ml}$ of streptomycin, and $4 \mathrm{mM} \mathrm{L-glutamine} \mathrm{(all} \mathrm{from}$ Invitrogen, Carlsbad, CA, USA) in a 24-well tissue culture plate in the presence of $10 \mathrm{IU} / \mathrm{mL}$ recombinant human IL-2 (rhIL-2, PeproTech, Rocky Hill, NJ, USA). The medium was changed every 2-3 days with fresh medium containing $10 \mathrm{IU} / \mathrm{ml} \mathrm{IL-2}$ with or without $5 \mathrm{ng} / \mathrm{mL}$ IL-21. After one week, $100 \mathrm{IU} / \mathrm{ml}$ of rhIL-2 and 5 $\mathrm{ng} / \mathrm{ml}$ of rhIL-15 (PeproTech, Rocky Hill, NJ, USA) were added to the medium, which was exchanged every other day. ADAM 17 inhibitor (TAPI-1, R\&D Systems, Minneapolis, MN, USA) or ADAM 10 inhibitor (GI 254023X, Biocompare, San Francisco, CA, USA) were treated during period of NK cells expansion. Expanded
NK cells cultured for 14-21 days were used for all experiments. Cell lines. The MCF-7, MDA-MB-231, and BT-474 cells were provided by American Type Culture Collection (ATCC, Manassas, VA, USA). These cells were cultured in complete RPMI 1640 medium supplemented with $10 \%$ heat inactivated FBS, $100 \mathrm{IU} / \mathrm{ml}$ penicillin, and $100 \mu \mathrm{g} / \mathrm{ml}$ streptomycin. The SKBR3 cells were cultured in complete Dulbecco's modified Eagle's medium (DMEM; Gibco, Carlsbad, CA, USA) supplemented with $10 \%$ heat inactivated FBS, $100 \mathrm{IU} / \mathrm{ml}$ penicillin, $100 \mu \mathrm{g} / \mathrm{ml}$ streptomycin. The IL-21 modified K562 cells were maintained in T-75 flask with RPMI 1640 supplemented with $10 \%$ heat inactivated FBS, 100 $\mathrm{IU} / \mathrm{ml}$ penicillin, $100 \mu \mathrm{g} / \mathrm{ml}$ streptomycin, and $4 \mathrm{mM} \mathrm{L}$-glutamine. When the cancer cells reached $80-90 \%$ confluence, cells were detached by dissociation with TrypLE Express (Gibco, Carlsbad, CA, USA) and incubated at $37^{\circ} \mathrm{C}$ and $5 \% \mathrm{CO}_{2}$ for $4 \mathrm{~min}$. RPMI 1640 containing $10 \%$ FBS was then added to neutralize the dissociation agent. Cells were centrifuged to collect pellet. These pellets were re-suspended with complete RPMI 1640 medium. Cells were stained with Trypan blue (Gibco, Carlsbad, CA, USA), and counted using a hemocytometer (Marienfeld, Lauda - Konigshofen, Germany) and a microscope (Leica, Wetzlar, Germany).

Flow cytometry. The expression of uncleaved receptors on the membranes of expanded NK cells was estimated by flow cytometry. NK cells $\left(1 \times 10^{5}\right)$ were washed with $1 \mathrm{X}$ phosphate buffered saline (PBS; Gibco, Carlsbad, CA, USA) containing $0.5 \%$ bovine serum albumin (BSA; Sigma Aldrich, St. Louis, MO, USA) and stained with a specific antibody for each phenotype of human NK cells such as CD16, NKp30, NKp46 (BD Biosciences, San Jose, CA, USA) or an isotype matched control antibody for 15 minutes on ice. Samples were washed with $1 \mathrm{X}$ PBS containing $0.5 \%$ BSA and stained cells were fixed in buffer containing $2 \%$ paraformaldehyde. Cells were analyzed using a FACS Calibur (BD Biosciences, San Jose, CA, USA). Data were analyzed by FlowJo V10.2 (FlowJo).

HER2-mediated ADCC assay. The SKBR3, MCF7, MDA-MB231 and BT474 cell lines, representing four subcategories of breast cancer (15), were used for the ADCC assay. Target tumor cells $\left(4 \times 10^{4} /\right.$ well) were cultured in a 96 wells-plate overnight at $37^{\circ} \mathrm{C}$ and $5 \% \mathrm{CO}_{2}$ to $80-90 \%$ confluency. The target cells were then removed, re-suspended in medium and incubated with $100 \mu \mathrm{g} / \mathrm{mL}$ of an antiHER2 antibody (Trastuzumab; Roche-Genentech, Basel, Switzerland) for 30 minutes at $37^{\circ} \mathrm{C}$ and $5 \% \mathrm{CO}_{2}$. NK cells $\left(8 \times 10^{4}\right.$ cells $/ \mathrm{mL}$ ) were co-cultured with target cells at effector to target ratio of $2: 1$ for $3 \mathrm{~h}$ at $37^{\circ} \mathrm{C}$ and $5 \% \mathrm{CO}_{2}$. Live cells were visualized by incubating with $10 \mu \mathrm{L}$ WST- 8 for $1 \mathrm{~h}$. The reaction was stopped on ice and the absorbance was determined at $480 \mathrm{~nm}$. The percentage of lysed cells was calculated by the following formula:

$$
\% \text { Spectfic lysis }=\left[1-\frac{(\text { A450 of NK cell treated target cells })-(\text { A450 of NK cells only })}{(\text { A450 of target cells })-(\text { A450 of target cells without WST } 8)}\right] \times 100
$$

Intracellular staining. IFN- $\gamma$ expression by expanded NK cells treated with ADAM17 inhibitor was analysed by intracellular staining with the BD Cytofix/Cytoperm kit (BD Biosciences, San Jose, USA). The expanded NK cells $\left(1 \times 10^{5}\right)$ were treated with 0.1 $\mathrm{ng} / \mathrm{mL}$ phorbol- 12-myristate 13 -acetate (PMA), $1 \mu \mathrm{g} / \mathrm{mL}$ ionomycin and $1 \mathrm{X}$ Brefeldin A (eBioscience, San Diego, CA, USA) at $37^{\circ} \mathrm{C}$ for $2 \mathrm{~h}$ at $5 \% \mathrm{CO}_{2}$ followed by staining with FITC-conjugated antihuman CD3 Abs and APC-conjugated anti-human CD56 Abs (BD 

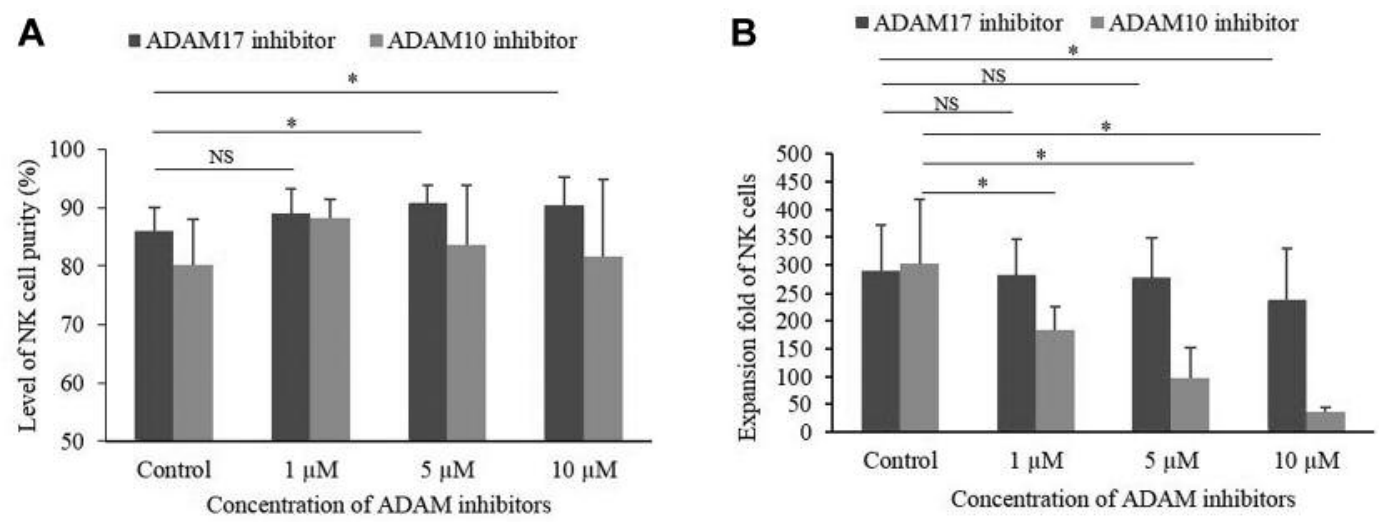

Figure 1. The effects of ADAM10 and ADAM17 inhibitors on the purity and expansion of NK cells. (A) Purity of NK cells treated with ADAM10 and ADAM17 inhibitors for 14 days. (B) Expansion fold of NK cells treated with ADAM10 and ADAM17 inhibitors. Data are represented as mean $\pm S D(n=5)$. Statistical significance was determined by the Wilcoxon test $\left({ }^{*} p<0.05\right.$; NS: not significant).

Biosciences, San Diego, CA, USA) for 20 min on ice. After washing, fixation, and permeabilization, NK cells were further stained with PE-conjugated anti-human IFN- $\gamma$ Ab (BD Biosciences, San Diego, CA, USA) on ice for 30 min, washed and analysed using the flow cytometry.

Statistical analysis. All results were analyzed by SPSS 16.0 software (IBM Corp., Armonk, NY, USA). The nonparametric Wilcoxon test was used to estimate significance of difference. Statistically significant differences are defined as $p<0.05$.

\section{Results}

ADAM inhibitors affect the purity and expansion rate of $N K$ cells. The roles of ADAM10 and ADAM17 inhibitors on NK cells were investigated in vitro. The results showed that 5 and $10 \mu \mathrm{M}$ of the ADAM17 inhibitor significantly increased the purity of NK cell $(p=0.043)$ compared to the control group (Figure 1A). There was no significant difference in the rate of expansion when NK cells were treated with 1 or $5 \mu \mathrm{M}$ of ADAM17 inhibitor. However, $10 \mu \mathrm{M}$ of the ADAM17 inhibitor reduced the expansion rate of NK cells $(p=0.043$ ) (Figure 1B). Although, $1 \mu \mathrm{M}$ of the ADAM 10 inhibitor increased the purity of NK cells, 5 and $10 \mu \mathrm{M}$ of the ADAM 10 inhibitor did not increase the purity of NK cells significantly (Figure 1A). The expansion rate of NK cells was attenuated at 1,5 and $10 \mu \mathrm{M}$ ADAM 10 inhibitor $(p=0.043)$ (Figure 1B).

Effects of the ADAM17 inhibitor on the expression of CD16 and ADCC activity of NK cells. The mean fluorescence intensity of CD16 receptor was significantly increased after NK cells were treated with 1 or $5 \mu \mathrm{M}$ of ADAM17 inhibitor ( $p=0.046,0.028$, respectively). The ADAM17 inhibitor decreased ADAM17 cleavage activity, inhibiting the shedding of CD16 from NK cells and increasing its expression (Figure 2A and B). In contrast, ADAM10 inhibitor had no effect on the expression of CD16 receptor on NK cells (Figure 2C and D).

Natural killer cells target breast cancer depending on the expression of HER2 on cancer cell. In this study, there was a significant increase in cytotoxicity of $5 \mu \mathrm{M}$ ADAM17 inhibitor treated NK cells against MCF-7 breast cancer cells $(p=0.039)$ (Figure 3A). However, the ADCC activity of NK cell was not altered by treatment with trastuzumab, possibly because MCF-7 cell line belongs to luminal-A subtype of breast cancer with a low expression of HER2/neu. MDAMB-231 cells are a triple negative cell line that also has low HER2 expression. NK cells also did not efficiently lyse these cells (Figure 3B). The SKBR-3 and BT-474 cell lines exhibit high expression of HER2/neu in breast cancer. The ADAM17 inhibitor did not affect the NK cell-mediated lysis of SKBR-3, but their ADCC activity was significantly enhanced against SKBR-3 cells $(p=0.027)$ and BT-474 cells $(p=0.027$ ) (Figures 3C and D). Additionally, the lysis of BT474 cells was increased by cytotoxic NK cells treated with ADAM17 inhibitor $(p=0.027)$ (Figure 3D).

Influence of the ADAM 17 inhibitor on IFN- $\gamma$ expression in $N K$ cells. The expression of IFN- $\gamma$ by NK cells was stimulated by PMA and ionomycin and detected by intracellular staining. Representative data from a donor showed the augmentation of IFN- $\gamma$ in ADAM17 inhibitor treated NK cells (Figure 4). There was a significant difference in the expression of IFN- $\gamma$ between the untreated and ADAM17 inhibitor treated NK cells (69.3\% and $81.9 \%$ after $2 \mathrm{~h}$, respectively). After $24 \mathrm{~h}$, the percentages of 

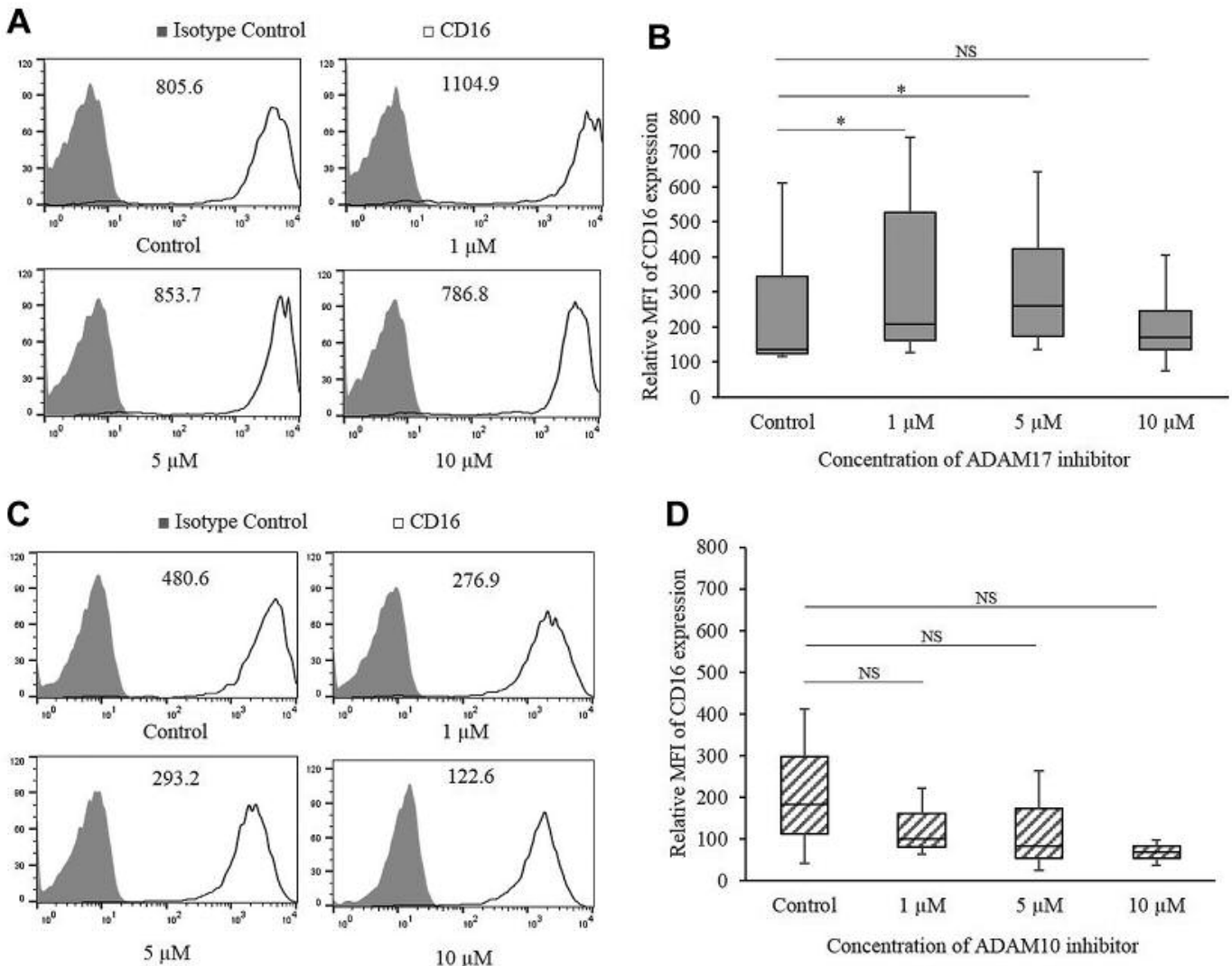

Figure 2. The expression of CD16 receptors on NK cells. (A) The relative mean fluorescence intensity (MFI) of CD16 receptor expressed in representative donor cells. The expanded NK cells were treated with ADAM17 inhibitor in IL-2 and IL-15-supplemented RPMI 1640 for 14 days. (B) The expression of $C D 16$ receptor on NK cells treated with ADAM17 inhibitor. (C) Representative donor cells expressed the relative MFI of CD16 on ADAM10 inhibitor treated NK cells. (D) The expression of CD16 receptor on NK cells treated with ADAM10 inhibitor. The results were shown in box and whisker plot indicating the median to relative MFI of CD16 receptor, with the whiskers indicating range ( $n=5$, each). The Wilcoxon test was used to analyse statistical significant difference $\left({ }^{*} p<0.05 ;\right.$ NS: not significant $)$.

untreated and ADAM17 treated NK cells expressing IFN- $\gamma$ were $76.5 \%$ and $83.3 \%$, respectively (Figure 4 ). These results showed that the ADAM17 inhibitor prompted IFN- $\gamma$ production by NK cells by $2 \mathrm{~h}$.

\section{Discussion}

NK cells were expanded from $\mathrm{CD}_{3} 4^{+}$hematopoietic progenitor cells in human $\operatorname{PBMC}(8,16,17)$. Co-culturing NK cells with K562 cells following stimulation with IL-2 and IL-15 resulted in over $90 \%$ purity of NK cells. The purity of NK cells was significantly augmented when treated with an ADAM17 inhibitor that prevented shedding of the CD16 domain on the surface. Inhibition of the ADAM17 enzyme did not influence NK cell expansion. Although a high concentration of the ADAM17 inhibitor $(10 \mu \mathrm{M})$ may have suppressed their proliferation. ADAM10 was demonstrated previously to be involved in modulating cell growth and to be expressed in some kinds of cancer $(12,18)$. Our results showed that inhibiting ADAM10 significantly reduced the proliferation of NK cells.

CD16 receptors are commonly expressed at a high level in CD56 ${ }^{\mathrm{dim}}$ and at a low level in CD56 ${ }^{\text {bright }} \mathrm{NK}$ cells (17). The regulation of CD16/Fc $\gamma$ RIIIA expression is associated with ADAM17 activity $(4,5,10)$. The current results implicate ADAM17 in modulating CD16 expression on NK cells. CD16 expression levels fluctuate depending on the blood donor and differentiation of NK cells (17).

Previous reports indicated that the expression of CD16 was associated with the differentiation of CD56 NK cells subsets $(17,19)$. Beziat et al. suggested that the high CD16 expression in the $\mathrm{CD} 56^{\mathrm{dim}}$ subset $\left(\mathrm{CD} 56^{\mathrm{dim}} \mathrm{CD} 16^{+}\right)$was differentiated from the $\mathrm{CD} 56^{\text {bright }} \mathrm{CD} 16^{-}$and $\mathrm{CD} 56^{\text {bright }} \mathrm{CD} 16^{+}$subsets (17). Each of the NK cell subsets responded to stages of innate 
A

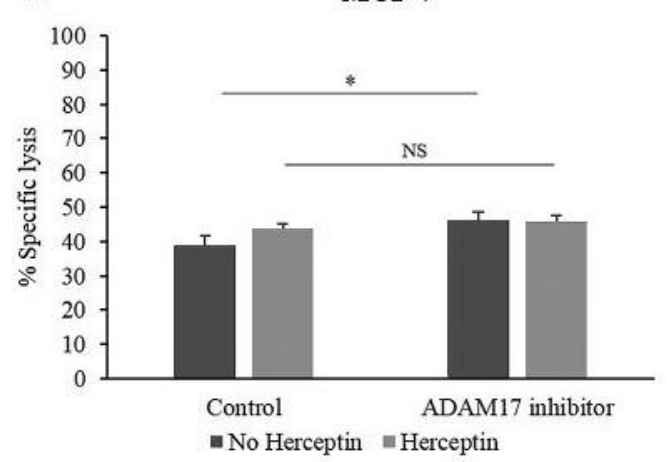

C

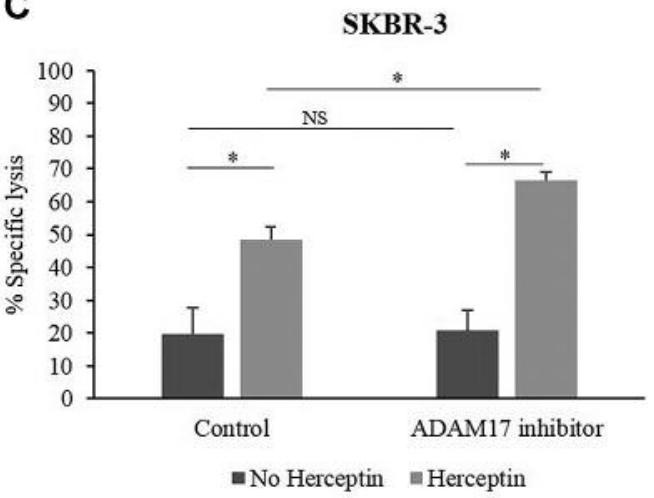

B

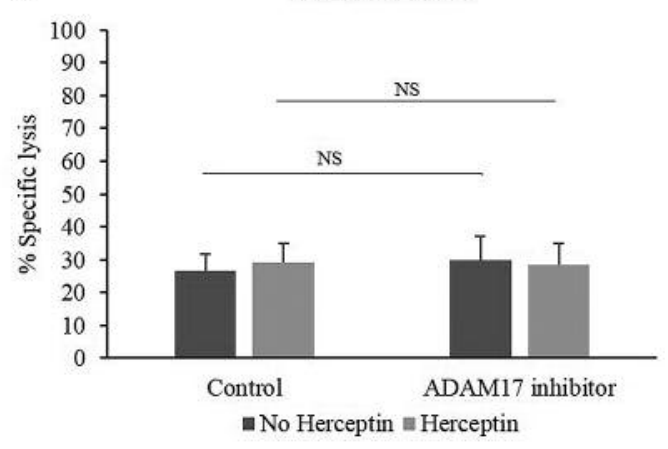

D

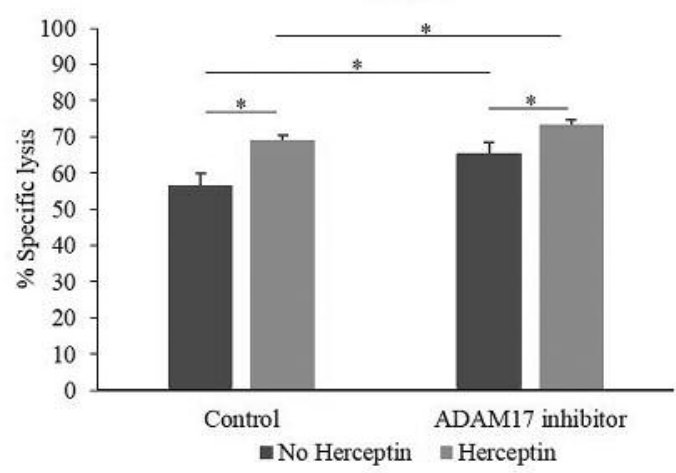

Figure 3. Effects of an ADAM17 inhibitor on the ADCC activity of NK cells. NK cells were incubated with target cells at a $2: 1$ ratio for 4 h at $37^{\circ} \mathrm{C}$ incubator. Cytotoxicity of NK cells against (A) MCF-7, (B) MDA-MB-231, (C) SKBR-3, and (D) BT-474 cells with or without $10 \mu \mathrm{g} / \mathrm{ml}$ trastuzumab. Data are presented as mean $\pm S D\left(n=6\right.$, each). The statistical significant difference was evaluated by Wilcoxon test $\left({ }^{*} p<0.05 ; N S:\right.$ not significant).

immunity. The early stage responsible for innate immunity, was characterized by CD56 ${ }^{\mathrm{dim}}$ because of rapid IFN- $\gamma$ production (20). Recently, ADAM17 cleavage was reported to modulate the loss of CD16 expression to augment the cytotoxicity of NK cell $(4,5,10,19)$. Therefore, the regulation of ADAM17 activity could control shedding of CD16 receptors to raise the level of ADCC. Additionally, aging affected the expression of CD16; cells from older individuals expressed higher levels of CD16 receptor than younger ones (17).

The ADCC activity of NK cells was mediated by the specific binding of an antibody to surface expressed CD16 (9, 11, 21). Cell lines with low HER2 expression did not undergo ADCC. However, inhibiting ADAM17 augmented significantly the ability of NK cells to lyse MCF-7 cells (Figure 3A). This suggested that the inhibition of ADAM17 enhanced the cytotoxicity of expanded NK cells to MCF-7 cells. Nevertheless, MDA-MB-231 cells were difficult to be lysed by cytotoxic NK cell.

ADCC activity was observed in trastuzumab-treated cell lines expressing high levels of HER2, such as SKBR-3 and BT-474. NK cells showed enhanced ADCC activity against
SKBR-3 and BT474 cells over 60\% (Figures 3C and D) at an $\mathrm{E}: \mathrm{T}$ ratio of 2:1. Our findings demonstrated that inhibition of ADAM17 enhanced the ADCC function of NK cells against HER2 expressing breast cancer cell lines.

Cytokine production is induced by the interaction of CD16 receptors with ligands on target cells that promote the release of IFN- $\gamma(20,22)$. IFN- $\gamma$ production by $\mathrm{NK}$ cells is stimulated by exogenous cytokines (IL-12 and IL-18) (4, 14, 23). The augmentation of CD16 expression relates to the production of IFN- $\gamma$ by NK cells. Our findings indicated that inhibition of ADAM17 stimulated IFN- $\gamma$ production thereby enhancing the cytotoxicity of NK cells. This was contrary to a previous report about the regulation of CD16 on NK cells by ADAM17 (4). This difference may be due to the fact that Romee et al. performed their experiment in CD56 ${ }^{\mathrm{dim}} \mathrm{NK}$ cells while we expanded NK cells from PBMC by stimulation with IL-2 and IL-15 which generated the CD56 ${ }^{\text {bright }} \mathrm{NK}$ subset as described by Freud et al. (24). Overall, the enhancement of IFN- $\gamma$ production by NK cells may be a potential immune-based treatment for cancer.

In conclusion, the inhibition of ADAM17 enhanced the 

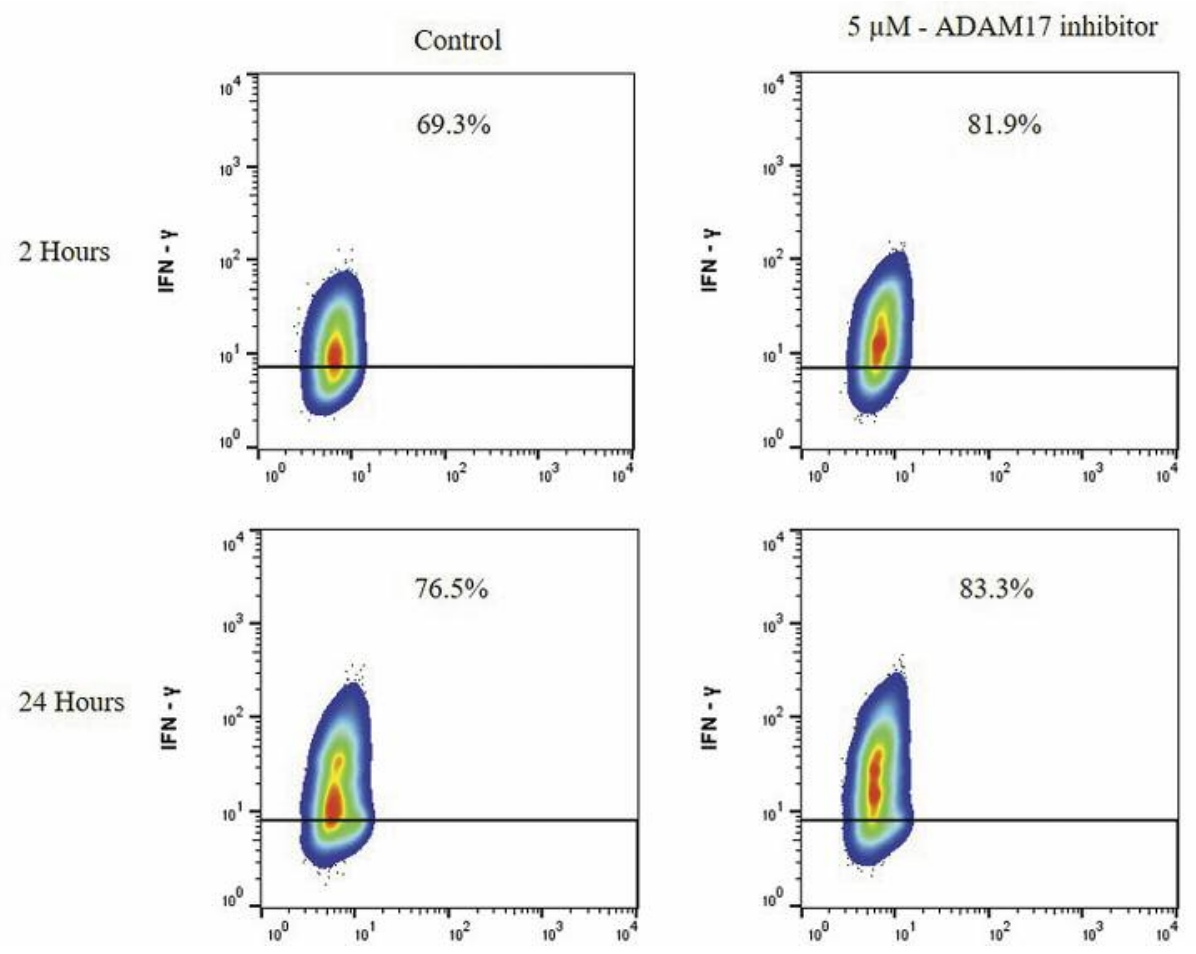

Figure 4. Influence of an ADAM17 inhibitor on IFN- $\gamma$ expression in NK cells. Expanded NK cells were incubated in medium for 2 and $24 h$ with or without PMA, Ionomycin and Brefeldin A to stimulate IFN- $\gamma$ secretion. The percentages of cell expressing IFN- $\gamma$ are shown.

purity of expanded NK cells and the ADCC activity of these cells against trastuzumab-treated breast cancer cell lines. Therefore, the inhibition of ADAM17 may be a novel immunotherapeutic approach for breast cancer. Future studies are needed to evaluate the in vivo efficacy of ADAM17 inhibitors in breast cancer therapeutics.

\section{Conflicts of Interest}

The Authors have no conflicts of interests to disclose.

\section{Acknowledgements}

This work was supported by a research grant from the Research Institute of Medical Sciences, Chonnam National University (2013CURIMS-DR004).

This study was supported by a grant (HCRI 14 015-1) Chonnam National University Hwasun Hospital Institute for Biomedical Science.

This study was supported by the National Research Foundation of Korea (NRF) grants (No. NRF-2015R1D1A3A01016860; M.H.P.)

\section{References}

1 Kessenbrock K, Plaks V and Werb Z: Matrix Metalloproteinases: Regulators of the Tumor Microenvironment. Cell 141: 52-67, 2010 .
2 Zhou Q, Gil-Krzewska A, Peruzzi G and Borrego F: Matrix metalloproteinases inhibition promotes the polyfunctionality of human natural killer cells in therapeutic antibody-based antitumour immunotherapy. Clin Exp Immunol 173: 131-139, 2013.

3 Scheller J, Chalaris A, Garbers C and Rose-John S: ADAM17: a molecular switch to control inflammation and tissue regeneration. Trends in Immunology 32: 380-387, 2011.

4 Romee R, Foley B, Lenvik T, Wang Y, Zhang B and Ankarlo D: NK cell CD16 surface expression and function is regulated by a disintegrin and metalloprotease-17 (ADAM17). Blood 121: 3599-3608, 2013.

5 Lajoie L: ADAM17-Mediated Shedding of FcgRIIIA on Human NK Cells: Identification of the Cleavage Site and Relationship with Activation. J Immunol 192: 741-751, 2014.

6 Lendeckel U, Kohl J, Arndt M, Carl-McGrath S, Donat H and Rocken C: Increased expression of ADAM family members in human breast cancer and breast cancer cell lines. J Cancer Res Clin Oncol 131: 41-48, 2005.

7 Chalaris A, Gewiese J, Paliga K, Fleig L, Schneede A, Krieger K, Rose-John S and Scheller J: ADAM17-mediated shedding of the IL6R induces cleavage of the membrane stub by gamma-secretase. Biochim Biophys Acta-Mol Cell Res 1803: 234-245, 2010.

8 Smyth MJ, Hayakawa Y, Takeda K and Yagita H: New aspects of natural-killer-cell surveillance and therapy of cancer. Nat Rev Cancer 2: 850-861, 2002.

9 Kroemer G, Senovilla L, Galluzzi L, Andre F and Zitvogel L: Natural and therapy-induced immunosurveillance in breast cancer. Nat Med 21: 1128-1138, 2015. 
10 Jing Y, Ni Z, Wu J, Higgins L, Markowski TW, Kaufman DS and Walcheck B: Identification of an ADAM17 cleavage region in human CD16 (FcgammaRIII) and the engineering of a noncleavable version of the receptor in NK cells. PLoS One 10: e0121788, 2015.

11 Childs RW and Carlsten M: Therapeutic approaches to enhance natural killer cell cytotoxicity against cancer: the force awakens. Nature Reviews Drug Discovery 14: 487-498, 2015.

12 Feldinger K, Generali D, Kramer-Marek G, Gijsen M, Ng TB, Wong JH, Strina C, Cappelletti M, Andreis D, Li JL, Bridges E, Turley H, Leek R, Roxanis I, Capala J, Murphy G, Harris AL and Kong A: ADAM10 mediates trastuzumab resistance and is correlated with survival in HER2 positive breast cancer Oncotarget 5: 6633-6646, 2014.

13 Jang YY, Cho D, Kim SK, Shin DJ, Park MH, Lee JJ, Shin MG, Shin JH, Suh SP and Ryang DW: An improved flow cytometrybased natural killer cytotoxicity assay involving calcein AM staining of effector cells. Ann Clin Lab Sci 42: 42-49, 2012.

14 Park YK, Shin DJ, Cho D, Kim SK, Lee JJ, Shin MG, Ryang DW, Lee JS, Park MH, Yoon JH and Jegal YJ: Interleukin-21 increases direct cytotoxicity and IFN-gamma production of ex vivo expanded NK cells towards breast cancer cells. Anticancer Res 32: 839-846, 2012.

15 Holliday DL and Speirs V: Choosing the right cell line for breast cancer research. Breast Cancer Res 13: 215, 2011.

16 Cho D and Campana D: Expansion and activation of natural killer cells for cancer immunotherapy. Korean J Lab Med 29: 89-96, 2009.

17 Beziat V, Duffy D, Quoc SN, Le Garff-Tavernier M, Decocq J, Combadiere B, Debre P and Vieillard V: CD56 ${ }^{\text {bright }} \mathrm{CD} 16^{+} \mathrm{NK}$ cells: a functional intermediate stage of NK cell differentiation. J Immunol 186: 6753-6761, 2011.
18 Armanious H, Gelebart P, Anand M, Belch A and Lai R: Constitutive activation of metalloproteinase ADAM10 in mantle cell lymphoma promotes cell growth and activates the TNFalpha/NFkappaB pathway. Blood 117: 6237-6246, 2011.

19 Grzywacz B, Kataria N and Verneris MR: CD56(dim)CD16(+) NK cells downregulate $\mathrm{CD} 16$ following target cell induced activation of matrix metalloproteinases. Leukemia 21: 356-359, 2007.

20 De Maria A, Bozzano F, Cantoni C and Moretta L: Revisiting: human natural killer cell subset function revealed cytolytic CD56(dim)CD16+ NK cells as rapid producers of abundant IFNgamma on activation. Proc Natl Acad Sci USA 108: 728-732, 2011.

21 Yeap WH, Wong KL, Shimasaki N, Teo EC, Quek JK, Yong HX, Diong CP, Bertoletti A, Linn YC and Wong SC: CD16 is indispensable for antibody-dependent cellular cytotoxicity by human monocytes. Sci Rep 6: 34310, 2016.

22 Ikeda H, Old LJ and Schreiber RD: The roles of IFN gamma in protection against tumor development and cancer immunoediting. Cytokine Growth Factor Rev 13: 95-109, 2002.

23 Fauriat C, Long EO, Ljunggren HG and Bryceson YT: Regulation of human NK-cell cytokine and chemokine production by target cell recognition. Blood 115: 2167-2176, 2010.

24 Freud AG, Becknell B, Roychowdhury S, Mao HC, Ferketich AK, Nuovo GJ, Hughes TL, Marburger TB, Sung J, Baiocchi RA, Guimond M and Caligiuri MA: A human CD34(+) subset resides in lymph nodes and differentiates into CD56 bright natural killer cells. Immunity 22: 295-304, 2005.

Received July 21, 2017

Revised August 24, 2017

Accepted August 28, 2017 